\title{
Histomorfologia do órgão acessório de perfuração de Thais haemastoma (Mollusca, Gastropoda)
}

\author{
Ana Valêsca P. Lima' \& Inês X. Martins² \\ 1. Laboratório de Histologia, Centro de Ciências da Saúde, Universidade de Fortaleza, Av. Washington Soares, 1321, Edson Queiroz, \\ 60811-341 Fortaleza, CE, Brasil. (avpl@unifor.br) \\ 2. Laboratório de Biologia Molecular e Genética (UNIFOR) e Curso de Pós-Graduação em Ciências Biológicas, Departamento de \\ Sistemática e Ecologia, Centro de Ciências Exatas e da Natureza, Universidade Federal da Paraíba. (ixmartins@unifor.br)
}

\begin{abstract}
Histology of the accessory boring organ in Thais haemastoma (Mollusca, Gastropoda). The mollusks of the family Thaididae are predators of others mollusks drilling their shell using alternately secretions from the accessory boring organ (ABO) and scraping movements of the radula. In this family the $\mathrm{ABO}$ is located in the median-anterior ventral part of the foot. The animals examined in the study were collected in the "Praia do Futuro", Fortaleza, Ceará, Brazil. The glandular part of ABO in Thais haemastoma (Linnaeus, 1758) is located in a cavity inside the foot, surrounded by foot muscle, and shows an excretory duct connecting that glandular portion to the outside. The analysis of microscopic sections stained by eosin-hematoxylin showed an epithelial tissue lining the cavity, and separating the glandular portion of ABO from the foot muscle. This ephitelial tissue is continuous with the excretory duct ephitelium. Under this tissue was observed a loose connective tissue. The ABO gland of T. haemastoma has a discoidal format and an irregular surface due to the presence of reentrances heading to the central part of the gland. The pseudoestratificated glandular epithelium with cylindrical and ciliated cells reacted negatively to the histochemical tests. Under the epithelium a connective loose tissue of support was observed.
\end{abstract}

KEYWORDS. Thaididae, ABO, histology, Brazil.

RESUMO. Os representantes da família Thaididae são organismos predadores de outros moluscos, perfurando suas conchas pela ação alternada de secreção oriunda do "Accessory Boring Organ" (ABO) e por raspagem através da rádula. Nesta família, o ABO está localizado na porção ventral mediano-anterior do pé. Os animais examinados neste estudo foram coletados na praia do Futuro, Fortaleza, em seguida levados ao laboratório para fixação e posterior tratamento histológico rotineiro. A porção glandular do ABO de Thais haemastoma (Linnaeus, 1758) se encontra alojada em uma cavidade circundada pela musculatura do pé e apresentando um ducto excretório que a comunica com o meio externo. Esta cavidade é revestida por um epitélio cilíndrico simples separando a porção glandular deste órgão do músculo pedioso, sendo contínuo com o epitélio de revestimento do ducto excretório. Subjacente a este tecido foi visualizado um tecido conjuntivo frouxo. A região glandular do $\mathrm{ABO}$ da espécie apresenta um formato discoidal com superfície irregular devido à presença de reentrâncias em direção à porção central da glândula. O epitélio glandular pseudoestratificado com células cilíndricas e ciliadas reagiu negativamente aos testes histoquímicos. Abaixo do epitélio, foi observado um tecido conjuntivo frouxo de sustentação.

PALAVRAS-CHAVE. Thaididae, ABO, histologia, Brasil.

Thais haemastoma (Linnaeus, 1758) pertence à família Thaididae e habita substrato consolidado na região entre-marés, próximo a bancos de ostras e cracas, da Carolina do Norte (EUA) ao Uruguai (Rıos, 1994).

Os membros das famílias Muricidae e Thaididae alimentam-se de suas presas usualmente fazendo um orifício na superfície da concha por aplicações alternadas de secreção oriunda do $\mathrm{ABO}$ (órgão acessório de perfuração) e raspagem com a rádula (Hughes, 1986). Os representantes destas famílias possuem o $\mathrm{ABO}$ localizado na porção ventral mediano-anterior do pé (PATTERSON EDWARD et al., 1992), diferente dos Naticidae que possuem o ABO na probóscide (CARRIKER, 1981).

Até o momento, não existem trabalhos histológicos do ABO em Thaididae. Para os muricídeos, CARRIKER \& VAN ZANDT (1972) descreveram o ABO sendo composto por um disco secretor central. CARRIKER (1981) concluiu que a forma ultraestrutural do $\mathrm{ABO}$ é a mesma nas várias espécies de Muricidae e Naticidae que estudou; observou que os organismos analisados conseguem imobilizar presas por meio de substâncias paralisantes liberadas pela glândula hipobranquial e possivelmente também por glândulas associadas com a probóscide, facilitando a ação de perfuração da concha.

Em estudos sobre o mecanismo químico de dissolução da concha de certas presas de naticídeos e muricídeos, CARRIKER \& Williams (1978) lançaram a hipótese de que esses organismos empregam uma combinação de enzimas, um ácido inorgânico e agentes quelantes em um meio hipertônico para facilitar a desintegração da concha e o transporte intracelular de cálcio durante a fase química de penetração nas conchas predadas.

Ao estudar o comportamento predatório de Thais haemastoma, MATTHEWs \& MATTHEWS-CASCON (1987) não mencionaram a utilização do $\mathrm{ABO}$, mas demonstraram que durante a predação da espécie sobre Crassostrea rhizophorae (Guilding, 1828), o gastrópode força a abertura das valvas da presa através da introdução do lábio externo, não utilizando sua rádula quando a investida era realizada in natura. Porém, se presas e vários predadores fossem colocados em um aquário, era possível observar apenas a utilização do órgão radular.

Objetiva-se descrever histomorfologicamente o órgão acessório de perfuração de Thais haemastoma. 


\section{MATERIAL E MÉTODOS}

Foram analisados 15 indivíduos de Thais haemastoma coletados na praia do Futuro, Fortaleza, Estado do Ceará, por meio de coleta direta aleatória na zona entre-marés, dentro da região do mesolitoral.

No laboratório, os animais coletados foram removidos da concha com o auxílio de um torno e o $\mathrm{ABO}$ foi retirado do pé, fixado em formaldeído a $4 \%$ por 24 horas. Após a fixação, as peças foram transferidas para álcool $70 \%$, posteriormente desidratadas em uma série ascendente de etanol, clarificadas por xilol e incluídas em parafina histológica.

Após a inclusão, foram feitos cortes sagitais com espessura de $5 \mu \mathrm{m}$, utilizando-se um micrótomo manual. Os cortes foram colocados em um aparelho de banho-maria a uma temperatura de $45^{\circ} \mathrm{C}$, coletados em lâminas e corados por métodos diferenciados.

Com o objetivo de descrever as características estruturais da glândula $\mathrm{ABO}$, foi empregado o método de coloração por Hematoxilina de Harrys e Eosina aquosa a $1 \%$ (Junqueira \& Junqueira, 1983). Para um estudo complementar de algumas propriedades histoquímicas do órgão, foram usados os testes de identificação da presença de carboidratos (PAS e Azul de Alcian) segundo Behmer et al. (1976). Dentre os carboidratos, mucopolissacarídios ácidos para o Azul de Alcian e glicoproteínas neutras para o PAS (com a utilização da amilase para o glicogênio).

Os exemplares analisados, bem como as lâminas utilizadas para as fotografias, encontram-se depositados sob o número 2129 na Coleção Malacológica do Departamento de Biologia da UFC.

\section{RESULTADOS}

$\mathrm{O}$ ABO de Thais haemastoma encontra-se alojado em uma cavidade na região anterior da sola do pé do animal e esta cavidade comunica-se com o meio externo por meio de um ducto excretório. Externamente ao $\mathrm{ABO}$ e a este ducto, foram observadas espessas camadas do músculo pedioso.

A cavidade é revestida por um epitélio cilíndrico simples aparentemente não-glandular e sem cílios. O tecido conjuntivo subjacente é frouxo e rico em células e feixes de fibras musculares provenientes do músculo pedioso. Estes feixes estão arranjados longitudinalmente logo abaixo do epitélio e, no restante da camada de tecido conjuntivo, encontram-se organizados de forma circular e perpendicular às fibras longitudinais.

De acordo com análises detalhadas dos cortes histológicos, o ABO é discoidal e de superfície irregular devido à presença de reentrâncias em direção à porção central da glândula (Fig. 1).

O órgão é revestido por epitélio pseudoestratificado com células glandulares cilíndricas e ciliadas, de núcleos oval-alongados e cromatina frouxa, indicando alta atividade secretória. Inseridas neste epitélio foram visualizadas células com núcleos arredondados e cromatina densa com pouco citoplasma circundante, localizadas em diferentes alturas do tecido, evidenciando características morfológicas semelhantes aos dos linfócitos (Fig. 2). Em alguns espécimes, as células epiteliais glandulares apresentaram citoplasma vacuolizado (Fig. 3). Não foi em todos os exemplares analisados que observou-se um limite definido entre este tecido epitelial e o conjuntivo de sustentação; nestes foi encontrado um predomínio de células conjuntivas mergulhadas em uma substância intercelular.

O padrão tecidual encontrado na parede da cavidade e do ducto excretório apresenta semelhanças morfológicas. O tecido epitelial de revestimento da cavidade e seus tecidos subjacentes são, portanto, contínuos aos tecidos encontrados no ducto excretório (Fig. 4).

No tecido conjuntivo do ducto também foram observados grupos de células glandulares denominadas mucócitos subdermais. Tais células são arredondadas, com citoplasma moderadamente acidofílico e núcleo central.

O epitélio cilíndrico simples do ducto e o conjuntivo subjacente são contínuos aos tecidos encontrados na região ventral do pé glandular. O tecido epitelial do pé possui células epiteliais ciliadas, com citoplasma basofílico associadas a mucócitos epiteliais que apresenta citoplasma pouco corado. Também há uma grande variedade e quantidade de mucócitos subdermais.

O epitélio glandular do $\mathrm{ABO}$ apresentou reação negativa ao Azul de Alcian. Houve, em poucas lâminas, reação positiva na porção subepitelial do ducto excretório, precisamente nos corpos celulares dos mucócitos subdermais, indicando a presença de mucopolissacarídios ácidos.

Nos cortes corados com PAS, bem como no controle amilase, foram obtidos resultados negativos indicando a ausência de glicoproteínas neutras.

\section{DISCUSSÃO E CONCLUSÕES}

A estrutura do ABO de Thais haemastoma constituída por um disco glandular central e um ducto excretório se assemelha em alguns pontos com as descrições realizadas para outras espécies de Muricidae que, supostamente, é uma família próxima a Thaididae e para a qual não há trabalhos histológicos do $\mathrm{ABO}$. A localização confere com a descrição de PATTERSONEDWARD et al. (1992) para os representantes da superfamília Muricoidea.

De acordo com Hyman (1967), o tecido epitelial do pé descrito para os gastrópodes é formado por células cuneiformes ciliadas e mucócitos, confirmando as descrições feitas neste trabalho para o epitélio pedioso.

No tecido conjuntivo frouxo abaixo do epitélio do ducto excretório encontram-se pequenos aglomerados de células glandulares subepiteliais conhecidos como mucócitos subdermais, que podem ter se originado das 

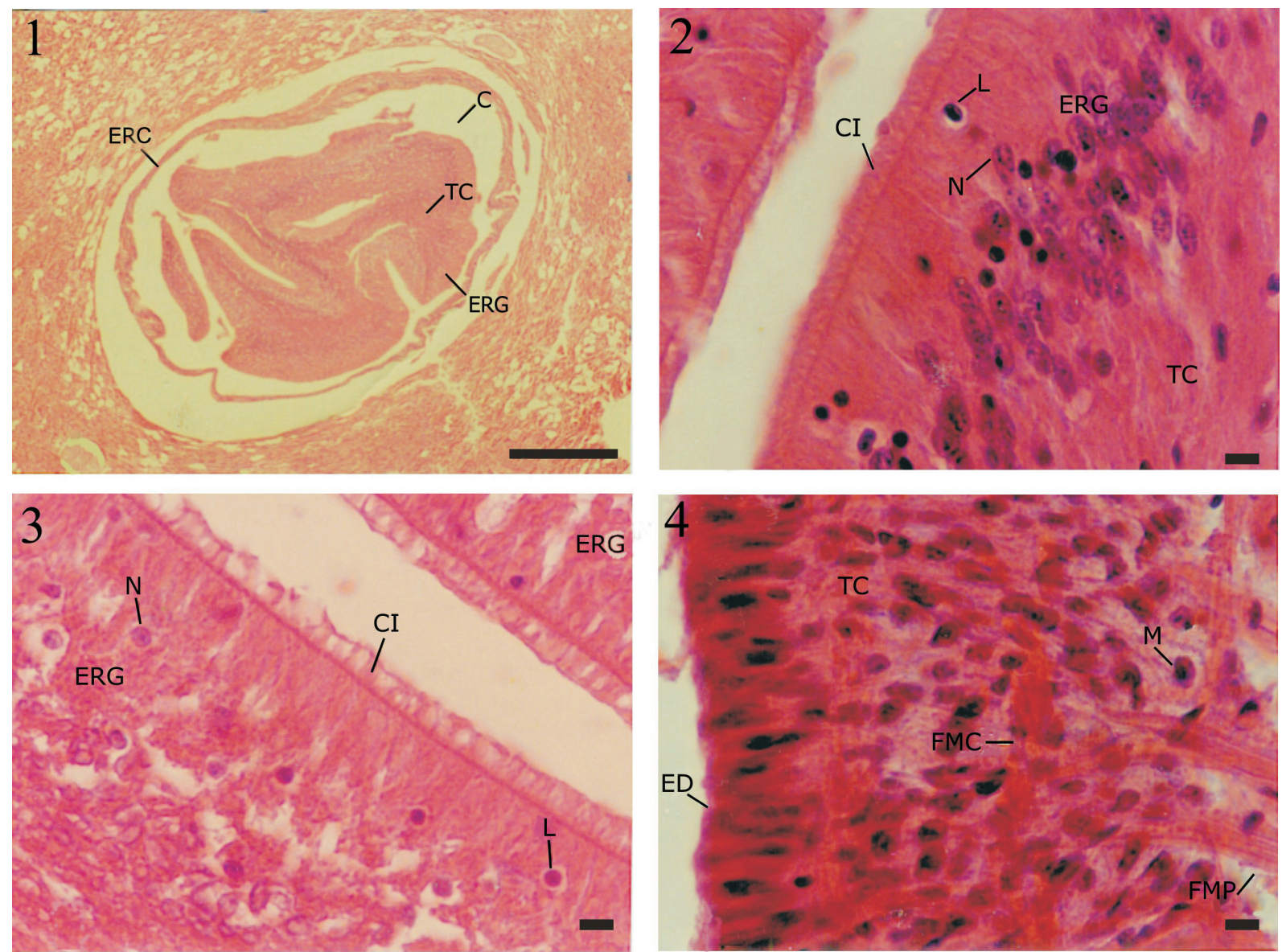

Figuras. 1-4. Fotomicrografia do órgão acessório de perfuração (ABO) de Thais haemastoma (Linnaeus, 1758). 1, Visão geral do órgão inserido no tecido pedioso; 2, epitélio glandular; 3, epitélio glandular vacuolizado; 4, parede do ducto excretório. (C, cavidade; CI, cílios; ED, epitélio do ducto; ERC, epitélio de revestimento da cavidade; ERG, epitélio de revestimento da glândula; FMC, fibras musculares circulares; FMP, fibras musculares perpendiculares; L, linfócitos; M, mucócitos; N, núcleo das células epiteliais; TC, tecido conjuntivo

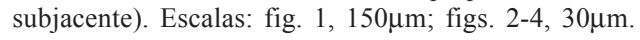

próprias células epiteliais que migraram e se organizaram em grupos subepiteliais. HyMAN (1967), na descrição histológica do pé, citou que esta estrutura frequentemente apresenta arranjos glandulares especiais. Mucócitos subdermais sustentados por filamentos de tecido conjuntivo fibroso e celular foram também observados por BERnARD \& BAgShaw (1969) para o ABO de Polinices lewisi (Gould, 1947).

A musculatura de toda a região do tecido conjuntivo frouxo do ducto auxilia na expulsão da secreção elaborada pelas células glandulares do ABO. $\mathrm{Na}$ contração da musculatura, os feixes musculares circulares atuam na diminuição do diâmetro da cavidade ductal e os feixes musculares longitudinais no encurtamento da mesma. HyMAN (1967) postulou que fibras musculares circulares e longitudinais são comuns delineando o epitélio de partes expostas do corpo em moluscos. Com relação aos feixes perpendiculares, estes devem atuar na manutenção da abertura da cavidade do ABO por tensão das próprias fibras.

O epitélio que reveste o órgão de Polinices lewisi foi descrito por BERnARD \& Bagshaw (1969) e de Urosalpix cinerea por CARRIKER \& WILLIAMS (1978); ambos são formados por células epiteliais colunares altas arranjadas em grupos que apresentam microvilos que aumentam em comprimento durante a atividade secretora; tais agrupamentos não foram observados no presente estudo.

NyLEN et al. (1969) sugeriram uma condição ativa e outra inativa para o ABO de uma espécie do gênero Urosalpinx e descreveram ainda que a arquitetura fundamental do epitélio secretor seria a mesma, mas o epitélio do ABO ativo se apresentaria diferenciado do restante dos tecidos pelo aumento no tamanho das células. Em Thais haemastoma verificou-se que a condição ativa da glândula está representada por um epitélio pseudo-estratificado, com células cilíndricas de núcleos com cromatina frouxa, indicando alta atividade metabólica de síntese protéica. A condição inativa pode estar representada por células vacuolizadas e mais curtas, observadas nos cortes histológicos.

Segundo Griesbach (1891), os linfócitos de gastrópodes prosobrânquios apresentam uma fina camada de citoplasma hialino que circunda o núcleo, semelhante ao tipo celular encontrado no ápice das células epiteliais de T. haemastoma.

Morton (1968), ao estudar células sanguíneas em moluscos, postulou que estes corpúsculos podem migrar para fora dos vasos sanguíneos e alcançar o epitélio do órgão. DREW \& CANTAB (1910) indicaram em seus trabalhos 
que células sangüíneas fagocíticas podem ingerir bactérias, e que esta pode ser a função dos linfócitos encontrados no epitélio do ABO para T. haemastoma, já que a glândula se encontra diretamente ligada ao meio externo pelo ducto excretório.

CARRIKer \& Williams (1978) revisaram a composição química da secreção liberada pelo ABO em naticídeos e muricídeos, citando as enzimas como principal componente. Os procedimentos de coloração histoquímica realizados inicialmente no $\mathrm{ABO}$ de $T$. haemastoma responderam negativamente para carboidratos e glicoproteínas neutras, sendo necessária a realização de outros testes específicos para evidenciar a composição química da secreção.

Agradecimentos. À ex-técnica do laboratório de histologia da UNIFOR, Mônica Café, pela preparação das lâminas; ao Prof. M.Sc. João Luiz Bastos (UFC), pelas fotomicrografias; à Dra. Helena Matthews Cascon (UFC), pelas sugestões ao texto; ao biólogo M.Sc. Carlos Augusto Meirelles pela diagramação das fotografias. A FUNCAP e UNIFOR pelo financiamento e espaço físico destinado à pesquisa.

\section{REFERÊNCIAS BIBLIOGRÁFICAS}

Behmer, O. A.; Tolosa, E. M. \& Neto, A. G. F. 1976. Manual de técnicas para histologia normal e patológica. São Paulo: Editora da Faculdade de Medicina da Universidade de São Paulo. 255p.

Bernard, F. R. \& Bagshaw, J. W. 1969. Histology and fine structure of the acessory boring organ of Polinices lewisi (Gastropoda, Prosobranchia). Journal of the Fisheries Research Board of Canada 26(06):1451-1457.

CARrIKer, M. R. 1981. Shell penetration and feeding by naticacean and muricacean predatory gastropods: a synthesis. Malacologia 20(2):403-422.
CARriker, M. R. \& VAn ZADT, D. 1972. Regeneration of the acessory boring organ of muricid gastropods after excision. Transactions of the American Microscopical Society 91:455-466.

Carriker, M. R. \& Williams, L. G. 1978. The chemical mechanism of shell dissolution by predatory boring gastropods: a review and na hypothesis. Malacologia 17(1):143-156.

Drew, G. H. \& Cantab, B. A. 1910. Some points in the phisiology of lamellibranch blood-corpuscles. Quarterly Journal of Microscopical Science 54:605-621.

Griesbach, H. 1891. Beiträge zur Histologie des Blutes. Archiv für Mikroskopische Anatomie und Entwicklungsmechanik 37:22-99.

Hughes, R. N. 1986. A functional biology of marine gastropod London, Croom Helm. 245p.

Hyman, L. M. 1967. The Invertebrates. VI. Mollusca I. Aplacophora, Polyplacophora, Monoplacophora, Gastropoda. The Coelomate Bilateria. New York; McGraw-Hill. 790p.

Junqueira, L. C. \& Junqueira, L. M. M. S. 1983. Técnicas Básicas de Citologia e Histologia. São Paulo, Livraria e Editora Santos. 123 p.

Matthews, H. R. \& Matthews-Cascon, H. 1987. Observação da predação de Thais haemastoma floridana (Conrad, 1837) sobre Crassostrea rhizophorae (Guilding, 1828). Arquivo de Ciências do Mar 26:47-50.

Morton, J. E. 1968. Molluses. London, Huthinson University Library. 244p.

Nylen, M. U.; Provenza, D. V. \& Carriker, M. R. 1969. Fine structure of the acessory boring organ of the gastropod, Urosalpinx. American Zoologist 9:935-965.

Patterson-Edward, J. K.; Xavier-Ramesh, M. \& AyakKannu, K. 1992. Comparative study of holes in bivalves, chipped and bored by the muricid gastropods Chicoreus ramosus, $C$. virgineus and Murex tribulus. Phuket Marine Biological Center Special Publication 11:106-110.

Rıos, E. C. 1994. Seashells of Brasil. Rio Grande, Fundação Universidade do Rio Grande. 492p.

Recebido em maio de 2006. Aceito em outubro de 2008. ISSN 0073-4721

Artigo disponível em: www.scielo.br/isz 